\title{
Factors associated with patient delay in accessing pulmonary tuberculosis care, Gezira State, Sudan, 2009
}

E.Y. Mohamed, ${ }^{1}$ S.M. Abdalla, ${ }^{2}$ A.A. Khamis, ${ }^{3}$ A. Abdelbadea ${ }^{4}$ and M.A. Abdelgadir ${ }^{5}$

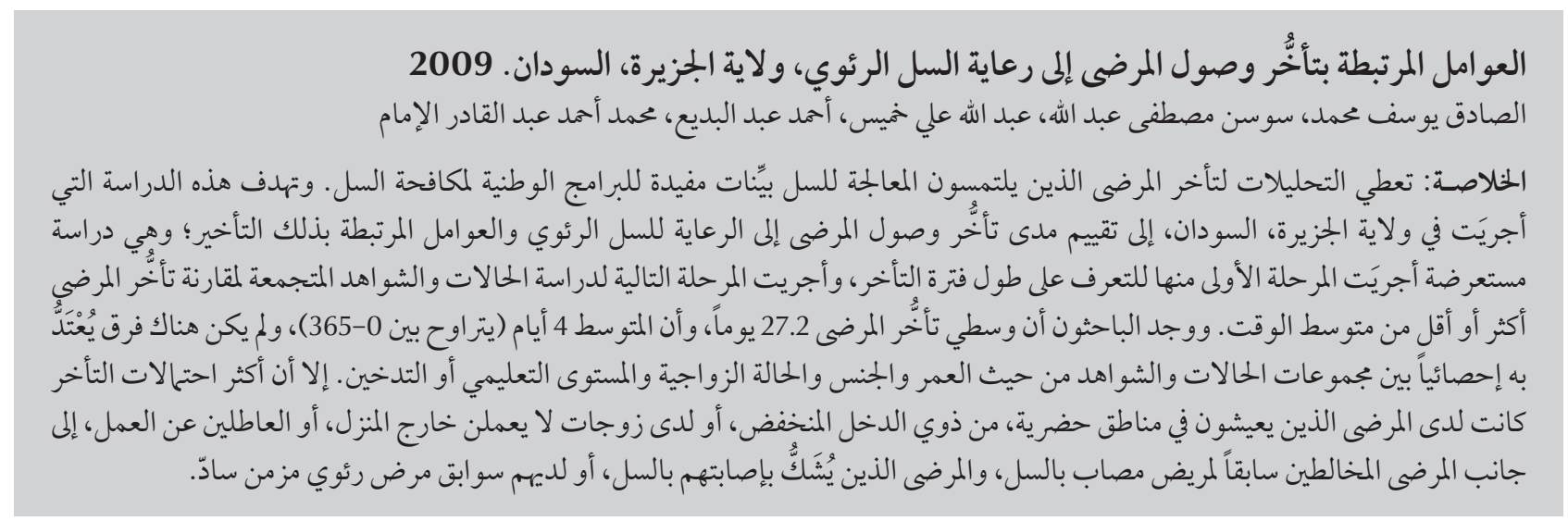

ABSTRACT Analyses of patient delays in seeking treatment for tuberculosis (TB) provide useful evidence for national TB control programmes. The objectives of this study in Gezira State, Sudan were to estimate the extent of, and factors associated with, pulmonary TB patient delay in accessing care. A cross-sectional phase was conducted to determine the length of delay, followed by a nested case-control phase comparing patients delaying above or below the median time. The mean patient delay was 27.2 days, median 4 days (range 0-365 days). There were no significant differences between case and control groups in terms of age, sex, marital status, educational level or smoking status. However, patients living in urban areas, with low income status and who were housewives or unemployed were more likely to delay. Also patients with a history of contact with a TB patient, those who suspected TB and those with a history of chronic obstructive pulmonary disease were more likely to delay.

Facteurs associés au retard d'accès des patients au traitement de la tuberculose pulmonaire dans l'État de Gezira (Soudan) en 2009

RÉSUMÉ L'analyse des retards dans la recherche de traitement antituberculeux par les patients fournit des éléments utiles aux programmes nationaux de lutte antituberculeuse. La présente étude, menée dans l'État de Gezira (Soudan), visait à estimer l'importance du retard d'accès aux soins des patients atteints de tuberculose pulmonaire ainsi que les facteurs associés à ce retard. Une phase transversale a été menée afin de déterminer l'importance du retard d'accès, suivie par une phase cas-témoins emboîtée comparant les patients dont le retard était inférieur au retard médian avec ceux dont le retard était supérieur. Le retard d'accès moyen des patients était de 27,2 jours et le retard d'accès médian de 4 jours (extrêmes 0-365 jours). Aucune différence significative n'a été observée entre le groupe d'étude et le groupe de témoin en termes d'âge, de sexe, de situation matrimoniale, de niveau d'études ou de statut tabagique. Toutefois, les patients vivant en milieu urbain, disposant de revenus faibles et qui étaient soit femmes au foyer, soit sans emploi avaient davantage tendance à retarder leur recherche de soins. De même, les patients ayant des antécédents de contact avec un patient tuberculeux, ceux qui suspectaient être atteints de la maladie et ceux souffrant de bronchopneumopathie obstructive chronique risqueraient davantage de repousser leur recherche de soins.

'Department of Community Medicine, Faculty of Medicine, University of Khartoum, Khartoum, Sudan (Correspondence to E.Y. Mohamed: elsadigoo@gmail.com).

${ }^{2}$ Department of Community Medicine; ${ }^{3}$ Department of Paediatrics; ${ }^{4}$ Department of Pathology; ${ }^{5}$ Department of Obstetrics and Gynaecology, Faculty of Medicine, National Ribat University, Khartoum, Sudan.

Received: 01/08/10; accepted: 22/03/11 


\section{Introduction}

Tuberculosis (TB) is still a major cause of death in both developed and developing countries [1]. In 2005, 12 million new cases of TB were identified, an almost $60 \%$ increase from the estimated number of cases in 1990 [2]. An effective $\mathrm{TB}$ control programme requires early diagnosis and immediate initiation of treatment. Delay in diagnosis is serious because it not only adversely affects disease prognosis at the individual level but also promotes transmission within the community and enhances TB epidemics $[3,4]$.

Delays in diagnosis and treatment of TB may reflect patient delays in seeking care, health care provider delays in making diagnosis and starting treatment, or both [5-11]. A delay in initiating $\mathrm{TB}$ care is not always the responsibility of the patient; sometimes patients contact the health services early but the physician in charge does not suspect TB [12]. It has been found that patients become more contagious as the delay progresses. The longest delays are associated with the highest numbers of Mycobacterium tuberculosis bacilli on sputum smears. Diagnostic delay may result in more advanced and severe disease, higher mortality and sustained spread of $M$. tuberculosis in the community as untreated people continue to transmit the infection to others $[13,14]$. The importance of delay is reflected in increasing costs and mortality due to TB. The many factors causing delay in diagnosis and treatment must be clearly identified and addressed locally in order to improve the quality and effectiveness of national TB control programmes (NTP). Studies analysing delays and their determinants provide useful evidence for assessment of case-finding success under DOTS.

The objectives of this study in Sudan were to estimate the extent of pulmonary TB patient delay in accessing care in Gezira State and to determine some of the factors associated with delays.

\section{Methods}

\section{Study area}

Gezira State, located in the centre of Sudan, is one of the high TB burden states in the country. The TB case detection rate was $37.9 \%$ in 2010 [15], which is far below the target of $70 \%$, developed by the Stop TB partnership and the World Health Assembly, and within the Millennium Development Goal framework [16]. TB care is provided through 41 TB management units (TBMUs) distributed throughout the State [17].

\section{Study design}

This was a cross-sectional and casecontrol study to explore patient delay in diagnosis and treatment of TB. A cross-sectional phase was conducted to determine the extent of delay, and then a nested case-control phase was carried out comparing patients delaying above and below the median time.

\section{Study population and sampling}

The study population was newly diagnosed (within 2 weeks) smear-positive pulmonary $\mathrm{TB}$ cases aged 15 years and older who attended the selected TBMUs during the study periods.

The sampling type was simple random. All the 41 TBMUs in the 5 localities were considered and 10 of them were selected randomly (i.e. 2 out of every 8 on average). Based on the estimated incidence of TB with a maximum allowed error of $10 \%$ and a $95 \%$ confidence interval (CI) the sample size was calculated as 282 and rounded up to 292 [18]. The sample was divided across the 5 localities according to population size by dividing the locality population over the total population of the state multiplied by the sample size. Within the TBMU, respondents were selected conveniently until the required sample was completed. The response rate was $100 \%$.

The cut-off point for long delays was defined according to the median delay of the sample. Patients with delays greater than the median were categorized as cases, while those with delays less than or equal to the median were considered as controls.

\section{Data collection techniques and tools}

Data was collected during June and December 2009 by health workers who underwent intense training on interviewing and probing techniques. Patients were interviewed using a precoded, pre-tested questionnaire. The questionnaire included information about patients' sociodemographic characteristics and selected factors that might affect delay in receiving $\mathrm{TB}$ care. The laboratory register was examined to confirm data regarding the time of diagnosis. The time taken to initiate treatment was calculated after the treatment was started.

A written consent was taken from the respondents. Ethical clearance was obtained from the Ministry of Health. Objectives, steps and expected outcomes of the research were explained to the participants as well as their right to withdraw from the study at any time without any consequences for their current care. Confidentiality of the data obtained were maintained before and during the study and will continue in the future.

\section{Data management and analysis}

Data analysis was performed using SPSS for Windows, version 13. Descriptive statistics were used, such as frequency, mean and standard deviation (SD), median, minimum and maximum. Comparisons between groups were made using the chi-squared test. $P$ value $<0.05$ was considered significant and all tests were 2-sided.

\section{Results}

The mean duration of patients' delay was 27.2 (95\% CI: 21.0-33.2) days. The median delay was 4 days (range 
0-365 days). There were 83 patients in the delayed group and 209 in the non-delayed group.

Table 1 shows the demographic characteristics of patients who delayed seeking care for TB compared with those who did not delay. There were no significant differences between the delayed and not delayed groups in terms of age, sex, marital status or educational level. However, there were significant differences by area of residence, occupation and income level. Patients living in urban areas were more likely to delay (45.3\%) than those in rural areas $(23.7 \%)(P<$ $0.001)$. Those who were housewives or unemployed (35.3\%) were more likely to delay than clerks and labourers (21.1\%), and students (17.4\%) $(P$ $=0.014)$. Patients with debts $(44.6 \%)$ or no income (50.0\%) were more likely to delay than those with income equal to expenditure $(17.2 \%)(P<$ 0.001).

Table 2 shows that patients with a history of contact with a TB patient were more likely to delay (38.7\%) than those who did not have contact (25.7\%) $(P=0.043)$. Patients who suspected TB were also more likely to delay (44.7\%) than those who had no suspicion of infection $(25.3 \%)(P=0.007)$, as did those with a history of COPD (60.0\%) versus those without $(27.3 \%)(P=$ $0.024)$. There was no significant difference in delay in care-seeking by smoking status.

\section{Discussion}

This study reported some extremely long delays between the onset of symptoms until presentation to a health care provider, ranging from 0 to 365 days. The mean duration was 27.2 days, which was lower than mean delays reported elsewhere in Sudan in Khartoum (53 days) [Mustafa $\mathrm{MH}$. unpublished document], the

\begin{tabular}{|c|c|c|c|c|c|c|c|}
\hline \multirow[t]{2}{*}{ Variable } & \multirow{2}{*}{$\begin{array}{c}\text { Total } \\
(n=292) \\
\text { No. }\end{array}$} & \multicolumn{2}{|c|}{$\begin{array}{c}\text { Delayed } \\
(n=83)\end{array}$} & \multicolumn{2}{|c|}{$\begin{array}{l}\text { Not delayed } \\
\qquad(n=209)\end{array}$} & \multirow[t]{2}{*}{$x^{2}$-test } & \multirow[t]{2}{*}{$P$-value } \\
\hline & & No. & $\%$ & No. & $\%$ & & \\
\hline \multicolumn{8}{|l|}{ Age (years) } \\
\hline $15-35$ & 160 & 46 & 28.8 & 114 & 71.3 & 0.16 & 0.899 \\
\hline$>35$ & 132 & 37 & 28.0 & 95 & 72.0 & & \\
\hline \multicolumn{8}{|l|}{ Sex } \\
\hline Male & 179 & 45 & 25.1 & 135 & 75.4 & 2.24 & 0.134 \\
\hline Female & 113 & 38 & 33.6 & 74 & 65.5 & & \\
\hline \multicolumn{8}{|l|}{ Education } \\
\hline University and above & 10 & 1 & 10.0 & 9 & 90.0 & 2.19 & 0.535 \\
\hline Basic and primary & 150 & 43 & 28.7 & 108 & 72.0 & & \\
\hline Illiterate and khalwa & 132 & 39 & 29.5 & 92 & 69.7 & & \\
\hline Residence & & & & & & 11.5 & $<0.001$ \\
\hline Urban & 64 & 29 & 45.3 & 35 & 54.7 & & \\
\hline Rural & 228 & 54 & 23.7 & 174 & 76.3 & & \\
\hline Occupation & & & & & & 14.3 & 0.014 \\
\hline Professional/technical & 9 & 3 & 33.3 & 6 & 66.7 & & \\
\hline Clerk/ labourer & 109 & 23 & 21.1 & 86 & 78.9 & & \\
\hline Student & 46 & 8 & 17.4 & 38 & 82.6 & & \\
\hline Housewife/ unemployed & 102 & 36 & 35.3 & 66 & 64.7 & & \\
\hline Other & 26 & 13 & 50.0 & 13 & 50.0 & & \\
\hline Income & & & & & & 23.5 & $<0.001$ \\
\hline Indebted & 65 & 29 & 44.6 & 36 & 55.4 & & \\
\hline No income & 42 & 21 & 50.0 & 21 & 50.0 & & \\
\hline Income $=$ expenses & 180 & 31 & 17.2 & 149 & 82.8 & & \\
\hline Saving & 5 & 2 & 40.0 & 3 & 60.0 & & \\
\hline Marital status & & & & & & 0.33 & 0.557 \\
\hline Married & 193 & 57 & 29.5 & 136 & 70.5 & & \\
\hline Single & 99 & 26 & 26.3 & 73 & 73.7 & & \\
\hline Total & 292 & 83 & 28.4 & 209 & 71.6 & & \\
\hline
\end{tabular}




\begin{tabular}{|c|c|c|c|c|c|c|c|}
\hline \multirow[t]{2}{*}{ Patient history } & \multirow{2}{*}{$\begin{array}{c}\text { Total } \\
(n=292) \\
\text { No. }\end{array}$} & \multicolumn{2}{|c|}{$\begin{array}{c}\text { Delayed } \\
(n=83)\end{array}$} & \multicolumn{2}{|c|}{$\begin{array}{l}\text { Not delayed } \\
\quad(n=209)\end{array}$} & \multirow[t]{2}{*}{$x^{2}$-value } & \multirow[t]{2}{*}{$P$-value } \\
\hline & & No. & $\%$ & No. & $\%$ & & \\
\hline \multicolumn{8}{|c|}{ Contact with a TB patient } \\
\hline Yes & 62 & 24 & 38.7 & 38 & 61.3 & 4.09 & 0.043 \\
\hline No & 230 & 59 & 25.7 & 171 & 74.3 & & \\
\hline History of smoking & & & & & & 0.03 & 0.858 \\
\hline Yes & 44 & 13 & 29.5 & 31 & 70.5 & & \\
\hline No & 248 & 70 & 28.2 & 178 & 71.8 & & \\
\hline Suspected TB & & & & & & 7.28 & 0.007 \\
\hline Yes & 47 & 21 & 44.7 & 26 & 55.3 & & \\
\hline No & 245 & 62 & 25.3 & 183 & 74.7 & & \\
\hline History of COPD & & & & & & 5.07 & 0.024 \\
\hline Yes & 10 & 6 & 60.0 & 4 & 40.0 & & \\
\hline No & 282 & 77 & 27.3 & 205 & 72.7 & & \\
\hline Total & 292 & 83 & 28.4 & 209 & 71.6 & & \\
\hline
\end{tabular}

$C O P D=$ chronic obstructive pulmonary disease .

Philippines and Ethiopia (30 and 30 days respectively) [19,20], but higher than in Egypt, Pakistan and Botswana (24.3, 9.9 and 21 days respectively) [21,22].

As regards the relation between patient delay and social factors [23], the study revealed similar proportions of younger and older age groups delaying seeking care. This finding was not in agreement with a study conducted in Khartoum state where older age groups delayed longer on average (50.2 versus 64.1 days) [Mustafa MH. unpublished document]. Slightly more women in our study delayed seeking TB care than did men but the difference was not significant. More women than men delayed in a study in Yemen [21]; but not in reports from Armenia and Brazil [24,25]. Patients living in rural areas were significantly more likely to delay than those living in urban areas [26].

A study in China found that less educated patients delayed longer [27], perhaps because they lacked the knowledge to help them seek care at the right time. In contrast, our study found no significant differences by educational level. However, we did find a significant difference in care-seeking by occupational and income status. Unemployed people and housewives were more likely to delay than other occupational groups [28] (professionals and technicians, clerks and labourers); students were the least likely to delay [29]. A study in California, United States, found that unemployment was one the factors independently predicting delay greater than 60 days [28]. Economic status seems to play an important role in patient delay to seek TB care, as those with no debts were less likely to delay than people with debts. These findings are in line with reports from the Philippines and Armenia [19,24].

This study found that the clinical history of patients had effects on delay in accessing TB care. Those who had had contact with TB patients delayed significantly more than those who had no contact [30]. Patients who suspected TB tended to delay more than those who did not. This may be due to stigma; patients who suspect TB may be afraid to consult a care provider while those who think that they are free of TB more confidently access care [26]. Patients who had history of COPD also delayed significantly more than those with a negative history [26]. This may be because patients with a history of COPD assume that their symptoms are due to COPD and hence they do not seek help.

Ou study found no relationship between smoking and delay in accessing care. Another study in Kampala found that one of the predictors of patient delay was smoking [26]. This may be due to the fact that cough appearing in TB patients who are smokers is often attributed to smoking, resulting in delays in seeking help for TB-related symptoms.

There were some limitations to the study. Patients' recall was needed to acquire data for the study and they may have had difficulty remembering events that occurred some time ago. However, as in other studies, there was no other way to obtain this type of data than patients' recall.

To summarize, the mean patient delay was long (27.2 days). There were no significant differences between the delayed and non-delayed groups in terms of age, sex, marital status or educational level or smoking status. 
However, there were significant differences by area of residence, occupation, income level, history of contact with a TB patient, history of COPD and having suspicion of pulmonary $\mathrm{TB}$.

\section{Acknowledgements}

We would like to acknowledge the National Tuberculosis Control Program for offering us the chance to conduct this work. We would also like to extend our thanks to Gezira Tuberculosis Control Programme and the staff at the localities who collected the data.

\section{References}

1. Dolin PJ, Raviglione MC, Kochi A. Global tuberculosis incidence and mortality during 1990-2000. Bulletin of the World Health Organization, 1994, 72:213-220.

2. Global tuberculosis control: surveillance, planning, financing. WHO report 2005. Geneva, World Health Organization, 2005 (WHO/HTM/TB/2005.349).

3. Dye $\mathrm{C}$ et al. Consensus statement. Global burden of tuberculosis: estimated incidence, prevalence and mortality by country. WHO Global Surveillance and Monitoring Project. Journal of the American Medical Association, 1999, 282:677-686.

4. Bjune G. Tuberculosis in the 21st century: an emerging pandemic? Norsk Epidemiologi, 2005, 15:133-139.

5. Sherman LF et al. Patient and health care system delays in the diagnosis and treatment of tuberculosis. International Journal of Tuberculosis and Lung Disease, 1999, 3:1088-1095.

6. Wandwalo ER, Morkve O. Delay in tuberculosis case-finding and treatment in Mwanza, Tanzania. International Journal of Tuberculosis and Lung Disease, 2000, 4:133-138.

7. Demissie M, Lindtjorn B, Berhane Y. Patient and health care service delay in the diagnosis of pulmonary tuberculosis in Ethiopia. BMC Public Health, 2002, 25:23.

8. Golub JE et al. Delayed tuberculosis diagnosis and tuberculosis transmission. International Journal of Tuberculosis and Lung Disease, 2006, 10(1):24-23

9. Ohmori $\mathrm{M}$ et al. Trends of delays in tuberculosis case finding in Japan and associated factors. International Journal of Tuberculosis and Lung Disease, 2005, 9:999-1005.

10. Xu B et al. Diagnostic delays in access to tuberculosis care in counties with or without the National Tuberculosis Control Program in rural China. International Journal ofTuberculosis and Lung Disease, 2005, 9:784-790.

11. Rojpibulstit M, Kanjanakiritamrong J, Chongsuvivatwong V. Patient and health system delays in the diagnosis of tuberculosis in Southern Thailand after health care reform. International Journal of Tuberculosis and Lung Disease, 2006, 10:422-428.

12. Yimer S, Bjune G, Alene G. Diagnostic and treatment delay among pulmonary tuberculosis patients in Ethiopia: a crosssectional study. BMC Infectious Diseases, 2005, 5:112.

13. Toman K. Tuberculosis case finding and chemotherapy questions and answers. Geneva, World Health Organization, 1979.

14. Styblo K. Epidemiology of tuberculosis. Selected papers. Volume 24. The Hague, KNCV Tuberculosis Foundation, 1991.

15. National tuberculosis control programme Sudan. Progress report. January-December 2010. Khartoum, Federal Ministry of Health, 2010:35.

16. Global tuberculosis control strategy 2009: epidemiology, strategy, financing. Geneva, World Health Organization, 2009.
17. TB control program. Annual report 2006. Khartoum, Federal Ministry of Health, 2006.

18. Fleiss JL. Statistical methods for rates and proportions. New York John Wiley and Sons, 1981

19. Auer $\mathrm{C}$ et al. Health seeking and perceived causes of tuberculosis among patients in Manila, Philippines. Tropical Medicine and International Health, 2000, 5:648-656.

20. Yimer S, Bjune G, Alene G. Diagnostic and treatment delay among pulmonary tuberculosis patients in Ethiopia: a crosssectional study. BMC Infectious Diseases, 2005, 5:112.

21. Diagnostic and treatment delay in tuberculosis: An in depth analysis of the health seeking behaviour of patients and health system response in seven countries of the East Mediterranean Region. Cairo, World Health Organization Regional Office for the Eastern Mediterranean, 2006 (WHO-EM/ TDR/009/E).

22. Steen TW, Mazonde GW. Pulmonary tuberculosis in Kwening district Botswana: delay in diagnosis in 212 smear positive patients. International Journal of Tuberculosis and Lung Disease, 1998, 2:627-634.

23. Schneider D et al. Reasons for delay in seeking care for tuberculosis, Republic of Armenia. Interdisciplinary Perspectives on Infectious Diseases, 2010:41262.

24. Schneider D et al. Reasons for delay in seeking care for tuberculosis, Republic of Armenia, 2006-2007. Interdisciplinary Perspectives on Infectious Diseases, 2010:412624.

25. Dos Santos MAPS et al. Risk factors for treatment delay in pulmonary tuberculosis in Recife, Brazil. BMC Public Health, 2005, 5:25

26. Kiwuwa MS, Charles K, Harriet MK. Patient and health service delay in pulmonary tuberculosis patients attending a referral hospital: a cross-sectional study. BMC Public Health 2005, $5: 122$

27. $\mathrm{Xu} \mathrm{B}$ et al. Diagnostic delays in access to tuberculosis care in counties with or without the National Tuberculosis Control Program in rural China. International Journal of Tuberculosis and Lung Disease, 2005, 9:784-790.

28. Asch $\mathrm{S}$ et al. Why do symptomatic patients delay obtaining care for tuberculosis? American Journal of Respiratory and Critical Care Medicine, 1998, 157:1244-1248.

29. Okeibunor JC et al. Where do tuberculosis patients go for treatment before reporting to DOTS clinics in southern Nigeria? Tanzania Health Research Bulletin, 2007, 9(2):94-101.

30. Salaniponi FM, Harries AD, Banda HJ. Care seeking behavior and diagnostic processes in patients with smear positive pulmonary tuberculosis in Malawi. International Journal of Tuberculosis and Lung Disease, 1991, 4:327-332. 